\title{
Application of fuzzy clustering analysis on the consumption level of residents by region in Hainan
}

\author{
Chen Yijuan \\ School of Mathematics and Statistics \\ Hainan Normal University \\ Haikou,China \\ E-mail:867146636@qq.com
}

He Lifang

School of Mathematics and Statistics

Hainan Normal University

Haikou,China

E-mail:634224845@qq.com

\author{
Zhang Chengyi* \\ School of Mathematics and Statistics \\ Hainan Normal University \\ Haikou,China \\ E-mail:chengyizh@sina.com
}

\begin{abstract}
The previous literatures generally study consumption level of the single urban or rural residents in Hainan.But there are few documents about the residents' consumption level in Hainan province. According to the the data in range of year 2003-2012,this paper analyzes and evaluates on consumption level of urban and rural residents in Hainan from the whole perspective. We compare and analyse the data of cities. The main conclusions are as follows: It unveils that the urban and rural resident consumption trend shows strong positive correlation to each respective local economic status. The education expense accounts for gradual increasing part of resident consumption cost. In addition, the population growth, the urbanization rate, and the income differentiation between urban and rural resident play a significant role in consumption behavior.The last, countermeasures and suggestions are offered for these phenomena and their reasons. And the result from this study provides references to the future urbanization planning.
\end{abstract}

Keywords-Hainan;Consumption Level;FCM Algorithm;

Fuzzy Cluster Analysis;Residents

\section{INTRODUCTION}

Study of the residents' consumption in terms of expense level and portion is expected to not only unveil the actual conditions of local people's livelihood, but also in turn to yield vital significance inputs to the strategic decisions in improving government investment, optimizing investment structure, and increasing domestic demand.The previous related literatures[1-7]

generally concluded the studies with respect to data from individual urban or rural in Hainan.But there are few documents about the residents' consumption level in Hainan.These researches select food, clothing, housing, supplies, medical, transportation, entertainment, miscellaneous goods, and services as indicators in modeling the consumption structure, but few takes the social development degree into account.

We think that statistics analysis of overall spending behavior in both urban and rural eras would give better understanding of the consumption structure. We therefore employed weighted FCM algorithm to carry out the analysis in this perspective.

We categorized the factors that drive consumption behavior as essential factors, major factors and other factors. We choose per capita GDP as the essential factor. The major factors included per capita disposable income of urban, per capita net income of rural, and the income difference between urban and rural eras. Other factor covers the number of university students the education funds , and urbanization rate and the natural population growth rate.

The weighted FCM algorithm was carried out to classify Hainan residents' consumption expenses. The classification results were subsequently discussed towards each driver. Recommendations were thereafter proposed to policy decision in future urbanization strategies.

\section{THE IMPROVED ALGORITHM}

\section{A. brief introduction fuzzy c-means clustering analysis} method

Bezdek has proved fuzzy c-means algorithm will be convergent from iterative calculation:

Step1: select class number $c(2 \leq c \leq n)$ and take an initial fuzzy classification matrix $R^{(0)} \leq M_{f c}$. Then the iteration step by step $l=0,1,2, \ldots$ 
Step2:To $R^{(l)}$ and calculate matrix clustering center $^{(l)}=\left(V_{1}^{(l)}, V_{2}^{(l)}, \ldots, V_{c}^{(l)}\right)^{T}$.In the formula

$$
V_{i}^{(l)}=\sum_{k=1}^{n}\left(r_{i k}^{(l)}\right)^{q} w_{k} u_{k} / \sum_{k=1}^{n}\left(r_{i k}^{(l)}\right)^{q} \text {. }
$$

Step3:Modify fuzzy classification matrix $R^{(l)}$, and take

$$
\begin{gathered}
r_{i k}^{(l)}=\left[\sum_{j=1}^{c}\left(\frac{\left\|w\left(u_{k}-V_{i}^{(l)}\right)\right\|}{\left\|w\left(u_{k}-V_{j}^{(l)}\right)\right\|}\right)^{\frac{2}{q-1}}\right]^{-1} \\
(k=1,2, \ldots n ; j=1,2, \ldots c),
\end{gathered}
$$

Step4:Compare $R^{(l)}$ with $R^{(l+1)}$.If the accuracy of fixed $\varepsilon>0$ has $\max \left\{\left|r_{i k}^{(l+1)}-r_{i k}^{(l)}\right|\right\} \leq \varepsilon$,so $R^{(l)}$ and $V^{(l)}$ are requested, and stop. Otherwise, $l=l+1$, back to the step2and repeated.

\section{B. improvement of algorithm}

We consider the role of index weight to the level of consumption in order to more appropriate to the needs of the actual situation in application. Assume that index weight vector is $w=\left(w_{1}, w_{2}, \ldots, w_{m}\right)$.So general European

power distance $\quad \sum_{j=1}\left(w_{j}\left(u_{j}-v_{i j}\right)\right]^{1 / 2}$ available to say the difference between the sample clustering ${ }^{u_{k}}$ and category ${ }{ }_{i}$.So in (1) the distance will be the improved generalized. European power distance.

\section{DATA ACQUISITION AND PROCESSING}

\section{A. data acquisition and determination of the weights}

In order to ensure the scientific nature of the study, data of this article from statistical yearbook of Hainan province.According to the information entropy method to determine the factors impact on the consumption level of importance weight

$$
\begin{gathered}
E_{j}=-k \sum_{i=1}^{m} p_{i j} \ln p_{i j}, \forall j \\
d_{j}=1-E_{j} \\
w_{j}=\frac{d_{j}}{\sum_{j=1}^{n} d_{j}}, \forall j
\end{gathered}
$$

By type(2),(3)and(4)to determine the entropy of each attribute $E_{j}$, the degree of difference ${ }^{d}$ and standardized weights ${ }^{w_{j}}$.Calculated separately and be shown in the table below:(down to one over ten thousand and we denote by $x_{1}$ Per Capita GDP(yuan), ${ }^{x_{2}}$ Per Capita Disposable Income of Urban(yuan), $x_{3}$ Per Capita Net Income of Rural(yuan), ${ }^{x_{4}}$ Income Difference Between Urban And Rural (yuan), $x_{5}$ Number of University Students(person), ${ }^{x_{6}}$ Education(10000yuan), ${ }^{x_{7}}$ Urbaniz ation Rate(\%), and ${ }^{x_{8}}$ Natural Growth Rate (\%))

TABLEI. SPECIFIC DATA OF ENTROPY, DIFFERENCE DEGREE AND WEIGHT

\begin{tabular}{ccccccccc}
\hline & $x_{1}$ & $x_{2}$ & $x_{3}$ & $x_{4}$ & $x_{5}$ & $x_{6}$ & $x_{7}$ & $x_{8}$ \\
\hline$E_{j}$ & 0.9825 & 0.9887 & 0.9912 & 0.9896 & 0.9776 & 0.9787 & 0.9925 & 0.9938 \\
$d_{j}$ & 0.0175 & 0.0113 & 0.0088 & 0.0104 & 0.0224 & 0.0213 & 0.0075 & 0.0062 \\
$w_{j}$ & 0.1657 & 0.1073 & 0.0838 & 0.0987 & 0.2130 & 0.2018 & 0.0708 & 0.0589 \\
\hline
\end{tabular}

Therefore, the weight of each index for: $\mathrm{W}=(0.1657$, $0.1073,0.0838,0.0987,0.2130,0.2018,0.0708,0.0589)$

\section{B. data normalization and determine the initial fuzzy classification matrix}

Different impact on the result of the classification because the characteristic parameters of dimension and order of magnitude is not necessarily the same.In order to eliminate the influence of different characteristic index order of magnitude.So use type(5) to normalize the data processing.

$$
\begin{aligned}
& u_{i j}^{\prime}=0.1+\frac{u_{i j}-m_{j}}{M_{j}-m_{j}} \times(0.9-0.1) \\
& i=1,2, \ldots, 144 ; j=1,2, \ldots, 10
\end{aligned}
$$

At the same time the corresponding initial fuzzy classification matrix $R^{(0)}$.And determine the classification number $^{c=4}$, take $^{q=2}$,precision $^{\varepsilon=0.001}$.

\section{C. clustering results}

The results from iterative calculation are summarized as in the below TABLEII.

TABLEII. CLUSTER CENTERS OF VARIOUS TYPE

\begin{tabular}{ccccccccc}
\hline Cluster & \multicolumn{7}{c}{ Indicators } \\
\cline { 2 - 9 } centers & $x_{1}$ & $x_{2}$ & $x_{3}$ & $x_{4}$ & $x_{5}$ & $x_{6}$ & $x_{7}$ & $x_{8}$ \\
\hline$V_{1}$ & 0.3985 & 0.6116 & 0.6323 & 0.5488 & 0.3320 & 0.2974 & 0.6006 & 0.5488 \\
$V_{2}$ & 0.6586 & 0.7911 & 0.8066 & 0.3530 & 0.4385 & 0.4258 & 0.6739 & 0.5811 \\
$V$ & 0.2930 & 0.4412 & 0.4389 & 0.7170 & 0.2071 & 0.1973 & 0.7100 & 0.5998 \\
$V_{4}$ & 0.2447 & 0.3361 & 0.4054 & 0.8748 & 0.1805 & 0.1681 & 0.4526 & 0.6836 \\
\hline
\end{tabular}


We defined the classification rule as that an object ${ }^{u_{k}}$ would be allocated to the closest vector clustering center. Therefore, the classification results are shown as in TABLEIII.

TABLEIII. OUTPUT OF CLUSTERING BY REGION IN HAINAN

\begin{tabular}{cc}
\hline Class & Region \\
\hline 1 & Wenchang, Qionghai, Chengmai, Lingao, Danzhou, Dongfang \\
2 & Haikou, Sanya \\
3 & Wuzhishan, Tunchang, Qiongzhong, Baoting, Whitesands, Changjiang \\
4 & Wanning, Ding'an, Ledong, Lingshui \\
\hline
\end{tabular}

The data and information from Hainan statistical yearbook indicate that the eight index of Haikou and Sanya are attributed with the values greater than the ones from Wenchang, Qionghai, Chengmai, Lingao, Danzhou and Dongfang, which are in turn greater than the rest eras. Wuzhishan, Tunchang, Qiongzhong, Baoting, White sands and Changjiang are ranked at the bottom. We brief it in the classification language that the class 2 is ranked as the highest level of consumption, the class 1 as higher, class 4 as lower, and class 3 seating itself at the lowest.

\section{ANALYSIS AND EVALUATION THE CLUSTERING RESULTS AND GIVING THE CORRESPONDING SUGGESTIONS}

The above argument would be submitted to following phenomena.

First: The clusters are classified consumption level in each era., Data in TABLEIV. reveal that the economic development aspects in Hainan province four aspects.For instance,economic development in Haikou and Sanya scores the highest. Qionghai, Chengmai, Wenchang, Danzhou and Wanning makes the second group, Baisha, Qiongzhong, Ledong, Lingao and Tunchang dominates the lowest. In addition, from the classification results and the data, we can know the level of consumption of class 2 is the highest, class 1 is the second and class 3 is the lowest.So the results of the classification and the economic development of cities and counties show strong relationship.

Second:Sanya, as the most developed city in term of tourism industry, exhibits higher economic level than other eras. As shown in TABLEV, Sanya's essential factors and main factor are comparable better, while the number of university student, the education investment, and urbanization rate in Sanya are comparable lower than in Haikou. The classification result categorizes the two cities in the same class that induces the education expenses contributing to a larger proportion of residents' consumption. This statement as well can be proved by the weight.

Third:A Data from Haikou and Danzhou (see TABLEV.) are similar, but the two cities are not in the same class. The reason is that the urbanization rate in Danzhou is low and the population growth rate, in the contory, is higher.Thus, the population growth and urbanization rate are also the influencing factors that determine residents' consumption level.

TABLEIV. COMPOSITE SCORES OF REGIONAL ECONOMIC DEVELOPMENT IN HAINAN

\begin{tabular}{|c|c|c|c|c|c|}
\hline Region & $\begin{array}{c}\text { Synthesis } \\
\text { Scores }\end{array}$ & Ranking & $\begin{array}{c}\text { Economic } \\
\text { Benefits }\end{array}$ & $\begin{array}{c}\text { Economic } \\
\text { Scale } \\
\end{array}$ & $\begin{array}{l}\text { Economic } \\
\text { Structure }\end{array}$ \\
\hline Average of Eastern group & 55.85 & & 60.63 & 51.96 & 59.43 \\
\hline Qionghai & 58.17 & 3 & 59.58 & 57.10 & 58.99 \\
\hline Wanning & 53.52 & 7 & 61.68 & 46.82 & 59.88 \\
\hline Average of South group & 54.75 & & 61.53 & 48.87 & 61.01 \\
\hline Sanya & 95.92 & 1 & 100.00 & 94.69 & 92.14 \\
\hline Lingshui & 49.10 & 9 & 52.66 & 46.99 & 49.18 \\
\hline Baoting & 42.29 & 11 & 47.97 & 34.08 & 58.25 \\
\hline Ledong & 31.70 & 16 & 45.50 & 19.73 & 44.47 \\
\hline Average of Western group & 44.85 & & 50.30 & 42.95 & 40.63 \\
\hline Danzhou & 54.04 & 6 & 54.32 & 56.15 & 46.63 \\
\hline Lingao & 35.26 & 15 & 46.16 & 28.21 & 37.50 \\
\hline Changjiang & 49.98 & 8 & 50.63 & 53.37 & 37.67 \\
\hline Dongfang & 40.10 & 12 & 50.08 & 34.09 & 40.73 \\
\hline Average of Northern group & 59.06 & & 59.97 & 57.10 & 63.69 \\
\hline Haikou & 85.85 & 2 & 67.99 & 91.95 & 100.00 \\
\hline Wenchang & 55.00 & 5 & 59.80 & 52.49 & 54.04 \\
\hline Ding'an & 40.00 & 13 & 51.59 & 27.79 & 57.77 \\
\hline Chengmai & 55.37 & 4 & 60.51 & 56.19 & 42.93 \\
\hline
\end{tabular}




\begin{tabular}{|c|c|c|c|c|c|}
\hline Average of central group & 34.56 & & 42.16 & 23.74 & 55.40 \\
\hline Wuzhishan & 43.63 & 10 & 43.24 & 33.43 & 77.65 \\
\hline Qiongzhong & 29.85 & 17 & 37.82 & 18.61 & 51.37 \\
\hline Tunchang & 35.86 & 14 & 47.49 & 23.42 & 54.33 \\
\hline Baisha & 28.91 & 18 & 40.10 & 19.51 & 38.24 \\
\hline
\end{tabular}

Source: Thematic analysis of Hainan province and Hainan statistical yearbook --2011.

TABLEV. CONTRAST OF DATA(HAIKOU, SANYA, DANZHOU)

\begin{tabular}{ccccccccc}
\hline Region & $x_{1}$ & $x_{2}$ & $x_{3}$ & $x_{4}$ & $x_{5}$ & $x_{6}$ & $x_{7}$ & $x_{8}$ \\
\hline Haikou & 35338 & 19730 & 7191 & 12539 & 29003 & 95291 & 60.08 & 1.22 \\
Sanya & 42236 & 20472 & 7582 & 12890 & 10385 & 46150 & 50.34 & 1.98 \\
Danzhou & 39716 & 16789 & 6781 & 10008 & 19501 & 40388 & 37.49 & 2.18 \\
\hline
\end{tabular}

Source: Hainan statistical yearbook --2012,Hainan bureau of statistics,NBS survey office in Hainan

Fourth: The income difference between urban and rural eras takes the role as the contribution factor that influences classification result. The data from Hainan statistical yearbook shows that both Lingao and Changjiang are underdeveloped eras, while Changjiang plays higher among the two (see TABLEVI.). However, Lingao, is assigned to class 1 with wenchang, qionghai, ChengMai, danzhou and Orient together, and ChangJiang is in class 3. It is noticeable that urban-rural income difference in ChangJiang, seating the third among 18 eras, is wider than in Lingao. This scenario differentiates Changjiang from Lingao and its counter partner eras in the class 1, though the latter economic level is low. In summary to this argument, the level of consumption shows a strong positive correlation with the economic development; the mean time,the income gap between urban and rural areas is a significant influencing factor that corrects residents' consumption level.

TABLEVI. CONTRAST OF DATA BETWEEN LINGAO DAN CHANGJIANG

\begin{tabular}{ccccccccc}
\hline Region & $x_{1}$ & $x_{2}$ & $x_{3}$ & $x_{4}$ & $x_{5}$ & $x_{6}$ & $x_{7}$ & $x_{8}$ \\
\hline Lingao & 19612 & 15035 & 5542 & 9493 & 8924 & 29642 & 29.34 & 1.72 \\
Changjiang & 32576 & 18033 & 5684 & 12349 & 4769 & 18347 & 34.84 & 0.76 \\
\hline
\end{tabular}

Source: Hainan statistical yearbook --2012,Hainan bureau of statistics,NBS survey office in Hainan

Fifth:The data in TABLEVII.show consumption level in Hainan central region, including Wuzhishan, Qiongzhong, Tunchang and Baisha, is the lowest.The values are small, and all of the four eras are assigned to class 3 . It is justifiable that the central eras, though rich in ecological resources, is with closed economies dominated in long term that caused considerably underdeveloped, and the residents' education expenses are less than in other eras.

TABLEVII. STATISTICS OF EIGHT INDICATORS BY REGION IN HAINAN

\begin{tabular}{|c|c|c|c|c|c|c|c|c|}
\hline Region & $x_{1}$ & $x_{2}$ & $x_{3}$ & $x_{4}$ & $x_{5}$ & $x_{6}$ & $x_{7}$ & $x_{8}$ \\
\hline \multicolumn{9}{|l|}{ North } \\
\hline Haikou & 35338 & 19730 & 7191 & 12539 & 29003 & 95291 & 60.08 & 1.22 \\
\hline Wenchang & 26676 & 17985 & 7248 & 10737 & 10607 & 32974 & 20.48 & 1.59 \\
\hline Ding'an & 16511 & 16430 & 5954 & 10476 & 6097 & 25758 & 28.88 & 0.79 \\
\hline Chengmai & 31389 & 17829 & 7212 & 10617 & 10091 & 30470 & 33.91 & 1.13 \\
\hline $\begin{array}{l}\text { South } \\
\text { Sanya }\end{array}$ & 42236 & 20472 & 7582 & 12890 & 10385 & 46150 & 50.34 & 1.98 \\
\hline Lingshui & 22113 & 15003 & 5415 & 9588 & 6740 & 21279 & 26.22 & 1.95 \\
\hline Baoting & 16240 & 15300 & 4482 & 10818 & 3102 & 13210 & 46.56 & 1.93 \\
\hline Ledong & 15174 & 14257 & 5925 & 8332 & 9704 & 36134 & 27.83 & 1.03 \\
\hline \multicolumn{9}{|l|}{ East } \\
\hline Qionghai & 27615 & 17477 & 7220 & 10257 & 8961 & 26167 & 30.16 & 1.07 \\
\hline $\begin{array}{c}\text { Wanning } \\
\text { West }\end{array}$ & 21857 & 17470 & 6933 & 10537 & 10970 & 31888 & 30.32 & 0.22 \\
\hline Ligao & 19612 & 15035 & 5542 & 9493 & 8924 & 29642 & 29.34 & 1.72 \\
\hline Danzhou & 39716 & 16789 & 6781 & 10008 & 19501 & 40388 & 37.49 & 2.18 \\
\hline Dongfang & 23722 & 16987 & 6372 & 10615 & 8020 & 30391 & 25.1 & 1.39 \\
\hline Changjiang & 32576 & 18033 & 5684 & 12349 & 4769 & 18347 & 34.84 & 0.76 \\
\hline
\end{tabular}




\begin{tabular}{ccccccccc} 
Wuzhishan & 15257 & 13584 & 4780 & 8804 & 2017 & 6527 & 46.31 & -1.37 \\
Qiongzhong & 14621 & 14593 & 4383 & 10210 & 4135 & 14147 & 47.21 & 1.12 \\
Tunchang & 15411 & 15123 & 5908 & 9215 & 5484 & 18413 & 34.58 & 1.54 \\
Baisha & 17716 & 15006 & 4738 & 10268 & 3623 & 13637 & 40.84 & 0.04 \\
\hline
\end{tabular}

Source: Hainan statistical yearbook --2012,Hainan bureau of statistics,NBS survey office in Hainan

Based on the above arguments, we derive the following suggestions.

The first: More high quality education is required to satisfy the people; the mean time,promote education investment.These project is established in terms the three strategic sides.First,to consolidate the fundamental educations.Second,to expedite the construction of vocational training institutes.Finally to establish faculties and specialties per the local economic and industrial needs in the local colleges and universities.

The second:Narrow the income gap between urban and rural areas.First,constantly improve farmers rich peasants policy,and implement various subsidies.Second, we must vigorously develop modern agriculture.Third, we need to make full use of local advantages of resources, develop characteristic economy, especially support the agricultural product processing industry to expand farmers' employment,such as developing chicken of Wenchang, cattle of Hainan and sericulture of Qiongzhong.

The third:Control the growth of the population.In particular,although the economy of Danzhou,Sanya,Baoting and Lingshui is more developed, the residents' consumption level is not high because the population growth rate is high.Economy,culture,medical and health care are the main factors influencing population growth rate.Therefore,we should control the growth of population from the following three aspects.First,strengthen the propaganda of family planning.Second, to the personnel of super living, take economic punishment .Third, improve the medical and health level.

The fourth: narrow the gap between other regions and the central of Hainan. The central of Hainan is not only the national ecological protection area and ethnic minority areas,but also the important barrier of ecological environment in Hainan.It has rich natural tourism resources and cultural tourism resources. So if we want to raise the consumption level of residents in central,we can develop rich variety of natural ecological tourism resources and unique cultural ecological tourism resources from the view of sustainable development. Strengthen ecological function areas in central, give full play to the regional resource advantages, develop ecological tourism, focus on construction tourism projects of $\mathrm{Li}$ nationality and Miao nationality cultural,and develop mountainous planting and breeding. At the same time, we will continue to improve the ecological compensation and to support the construction of ecological functional areas in central.Finally increase the investment in the rural vocational education and skills training of migrant workers to train more skilled migrant workers.

\section{CONCLUSION}

In this paper,we select eight indicators from factors influencing the level of consumption , and use the weighted fuzzy c-means clustering algorithm in analyzing the residents' consumption in 18 eras in Hainan. By comparing the similarities, partial similarities, and differences in the statistic results from varies of eras, we identify each characteristics, differences and influencing factors. Consequently, we discuss these driving factors and propose corresponding suggestions to each phenomenon.

\section{ACKNOWLEDGMENT}

This work is supported by the National Natural Science Foundation of China (No.71361008) and Hainan special social development technology (Grant No. 2011SFO3).

\section{REFERENCES}

[1] Gao Jing-chun. Discuss consumer demand and development trend of residents in Hainan[J].Journal of Hainan Open University,2005(2):36-38.(in Chinese)

[2] Zhang Yu-mei,Lu Jiang-yong,Guo Jian Jian-chun.An Empirical Analysis of Urban Residents'Consumption Structure in Hainan Province[J].Journal of Anhui BusinessCollege(socialsciences),2005,4(4):24-27,67.(in Chinese)

[3] Guo Jian-chun,Zhang Yu-mei,Lu Jiang-yong.The determination of demand elasticity and its use in the marketing strategy--analysis on consumption demand of urban residents in Hainan[A].Academy of management annual conference 2006, the Chinese market for the fourth time proceedings of the national member of congress[C],2006,6(4):1842-1850.(in Chinese)

[4] Zou Wen-tao,Sun Rong-jun,Cai Lei etc.Empirical analysis on consumption structure of rural residents in Hainan province[J].Inner Mongolia Agricultural Science and Technology,2008(5):19-20.(in Chinese)

[5] Wang Yan-ying,Miao Jun-hong.Comparative study on consumption structure of the rural residents in Hainan province[J].Journal of Hainan Normal University(Natural Science), 2011,29(4):319-323.(in Chinese)

[6] Miao Jun-hong.Study on rural residents' consumption structure based on factor analysis and cluster analysis in Hainan[J].Journal of Hainan Open University,2012(1):68-71.(in Chinese)

[7] Zhou Jun-mei.Analysis on development trend of urban residents'consumption structure--Hainan Province[J]. a) Science, 2013(3):178,208.(in Chinese)

[8] Liu De-fen,Ji Li-wen,An Wen-juan.Evaluation on comprehensive consumption level of the region using principal component analysis and cluster analysis--based on studies of the urban household consumer expenditures from China's 31 provinces and cities.Popular Business,2010(116):14.(in Chinese)

[9] Mei Cui,Shan Pei.The cluster analysis of regional income gap and its consumption impact[J].Journal of Nanjing Audit University,2005,2(3):7-10.(in Chinese)

[10] Chen Shui-li,Li Jing-gong,Wang Xiang-gong.Fuzzy set theory and its application(the first Edition)[M].Science Press, 2005:94-118.(in Chinese) 